\title{
Negative Pressure Pulmonary Oedema Following Emergency Appendectomy under LMA: A Case Report
}

\author{
Tobi $\mathrm{KU}^{1^{*}}$, Akinniraye $\mathrm{OA}^{2}$ and Cole $\mathrm{AS}^{3}$ \\ ${ }^{1}$ Consultant Anaesthesiologist/Intensivist, Department of Anaesthesiology, University of Benin Teaching \\ Hospital, Benin City, Edo State, Nigeria \\ ${ }^{2}$ Consultant Intensivist, Department of Anaesthesia and Critical care, Lagoon Hospital, Lagos, Lagos State, Nigeria \\ ${ }^{3}$ Medical Officer, Department of Anaesthesia and Critical careLagoon Hospital, Lagos, Lagos State, \\ Nigeria
}

"Corresponding author: Tobi KU, Consultant Anaesthesiologist/Intensivist, Department of Anaesthesiology, University of Benin Teaching Hospital, Benin City, Edo State, Nigeria, Tel: 08033600018, E-mail: tobikingsley@yahoo.com

Citation: Tobi KU, Akinniraye OA, Cole AS (2018) Negative Pressure Pulmonary Oedema Following Emergency Appendectomy under LMA: A Case Report. SAJ Cas Rep 5: 301

Article history: Received: 23 April 2018, Accepted: 19 June 2018, Published: 20 June 2018

\begin{abstract}
Negative Pressure Pulmonary Oedema (NPPO) is an uncommon, potentially life-threatening complication of general anesthesia. It is said to even be less common with the use of a laryngeal mask airway (LMA).Mortality can be as high as $11-40 \%$. We present a 31 year old man who presented for emergency appendectomy under general anaesthesia with LMA who was managed in the ICU with judicious use of frusemide and positive pressure ventilation and was subsequently discharged after 48 hours.
\end{abstract}

Keywords: Negative Pressure Pulmonary Oedema; Intrathoracic Pressure; Laryngeal mask airway

\section{Introduction}

Negative Pressure Pulmonary Oedema (NPPO) is a potentially life-threatening complication of general anesthesia. It is an uncommon event with an incidence of 0.05 to $0.1 \%[1,2]$. And it is said to even be less common with the use of a laryngeal mask airway (LMA) [3,4].

Mortality following NPPO can be as high as $11-40 \%$ [5]. Unfortunately it can complicate the clinical course and outcome of otherwise healthy patients undergoing simple surgical procedures such as appendectomy. This may lead to prolonged endotracheal intubation and admission into intensive careunit. Early recognition and institution of appropriate positive pressure ventilation is germane to ensuring successful outcomes.

We present a 31 year old man who presented for emergency appendectomy under general anaesthesia with LMA who was managed in the ICU and discharged after 48 hours.

\section{Case report}

$\mathrm{K} \mathrm{O}$ is a 31 year old man who had emergency appendectomy under general anesthesia with LMA. Induction of anesthesia was with i.v.propofol $100 \mathrm{mg}$ with lidocaine and a size $8 \mathrm{~mm}$ laryngeal mask airway (LMA) was inserted. Correct placement was confirmed with bilateral chest auscultation and patient was connected to the anesthetic machine with incremental doses of isoflurane to maintain anaesthesia and allowed to breathe spontaneously.

Some few minutes intra-operatively, patient was observed to be restless and 20mg bolus of propofol was given and commenced on continuous infusion $(100 \mathrm{mg}$ ) in $500 \mathrm{ml}$ normal saline. Analgesia was maintained with pentazocine, paracetamol and ketorolac. He had a total of $1.5 \mathrm{l}$ of normal saline given at the rate of $10 \mathrm{ml} / \mathrm{kg} / \mathrm{hr}$.

Surgery lasted for about 40minutes and was uneventful. At the end of surgery, the patient's oropharynx was suctioned and the LMA was removed. Oxygen was administered at a rate of $10 \mathrm{~L} / \mathrm{min}$ via a facemask. However, shortly afterwards, he became restless and started coughing with oxygen saturation dropping to $88 \%$. He was placed in the lateral position and supplemental oxygen was continued via a Hudson's facemask and oxygen saturation improved remarkably. 
On examination, he had frothy secretions with streaks of blood from his mouth and nostrils and widespread crepitations on chest auscultation. His pulse rate was elevated at 130bpmthough the blood pressure remained at 139/90mmhg.Hisintravenous fluid was discontinued and a bolus dose of $80 \mathrm{mg}$ of frusemide was given.

An assessment of non-cardiogenic pulmonary oedema secondary to negative intrathoracic pressure was made. An arterial blood gas analysis $(\mathrm{ABG})$ was done which revealed hypercarbia and severe respiratory acidosis $\left(\mathrm{PH}-6.98, \mathrm{PCO}_{2}-110 \mathrm{mmHg}, \mathrm{PO}_{2}\right.$ $118 \mathrm{mmHg}$ ). He was then re-intubated with a size $7.5 \mathrm{~mm}$ endotrachael tube and i.v vecuronium $10 \mathrm{mg}$ administered and transferred to the Intensive Care Unit where he was placed on mechanical ventilator: (Mode - SIMV Volume control and $\mathrm{FIO}_{2}-1$ ). He was commenced on propofol and midazolam for sedation and IVF $0.9 \%$ normal saline $500 \mathrm{mls}$ alternate with $5 \%$ dextrose saline $500 \mathrm{mls}$ 6 hrly

After 24 hours in ICU, ABG improved markedly and patient was then extubated and CXR, FBC, E/U/Cr ordered. Post extubation, patient was awake and alert. Oxygen saturation - 100\% (oxygen via facemask) and patient commenced on graded oral sips. He was nebulized with albuterol and had incentive spirometry. He was transferred to the wards afterwards. He was discharged home after 4 days in the hospital and was scheduled for follow up visit 4 days later (Table 1).

\begin{tabular}{|c|c|c|c|c|c|}
\hline & 07-04-14 (2pm) & 07-04-14 (4pm) & 07-04-14 (8pm) & 08-04-14 (12am) & 08-04-14 (7am) \\
\hline $\mathbf{K}$ & 3.1 & 3.1 & 3.2 & 3.2 & 3.1 \\
\hline $\mathrm{Ca}$ & 0.63 & 0.67 & 0.71 & 0.64 & 0.79 \\
\hline $\mathrm{TCO}_{2}$ & 29.3 & 23.0 & 20.8 & 22.6 & 22.7 \\
\hline HCT & 54 & 52 & 48 & 46 & 39 \\
\hline PH & 6.98 & 7.31 & 7.43 & 7.41 & 7.44 \\
\hline $\mathrm{PCO}_{2}$ & 110 & 43 & 30 & 34 & 32 \\
\hline $\mathrm{PO}_{2}$ & 118 & 278 & 293 & 160 & 216 \\
\hline $\mathrm{FiO}_{2}$ & & & 0.8 & 0.6 & 0.6 \\
\hline $\mathbf{P} / \mathbf{f}$ & & & 366 & 266 & 360 \\
\hline $\mathrm{HCO}_{3}$ & 25.9 & 21.7 & 19.9 & 21.6 & 23.7 \\
\hline Lactate & 2.6 & 2.5 & 2.3 & 1.7 & 0.8 \\
\hline $\mathrm{Na}$ & 147 & & & 139 & \\
\hline $\mathbf{K}$ & 4.4 & & & 3.6 & \\
\hline $\mathrm{Cl}$ & 110 & & & 108 & \\
\hline $\mathrm{HCO}_{3}$ & 24 & & & 27 & \\
\hline Urea & 21 & & & 18 & \\
\hline $\mathrm{Cr}$ & 1.3 & & & 0.6 & \\
\hline
\end{tabular}

\section{Discussion}

Negative pressure pulmonary oedema was first described about 9 decades ago, however, possible association of LMA with the development of NPPO was first reported by Ezri, et al. Biting on an LMA during emergence from anaesthesia resulting in dyspnea and hemoptysis has also been previously reported $[3,6,7]$. This was likely the case in this report.

Negative pressure pulmonary oedema has been categorized into two distinct classes namely type I and type II: type I is associated with forceful inspiratory effort following an acute upper airway obstruction, while type II, and occurs after the relief of chronic partial airway obstruction [8]. Among the common causes of type I NPPO, laryngospasm is most common, accounting for approximately $50 \%$ of the reported cases [8-10]. Our patient developed laryngospasm after the removal of the LMA with resultant NPPO which the attending anesthetist failed to recognize promptly.

During emergency from anaesthesia, upper airway obstruction is usually followed by acute onset of respiratory distress, with or without hemoptysis, and features of bilateral pulmonary edema [11]. However, in some patients, the onset may be considerably delayed, up to a few hours [11]. Patients who developed laryngospasm during emergency from anaesthesia require closer and longer period of monitoring in the immediate postoperative period for signs of NPPO. An assessment of NPPO was made after close monitoring of this patient for some time in operating room. The attending anesthetist administered midazolam when the patient was restless which could contribute to hypoventilation and carbon dioxide accumulation.

Some patients' characteristics increase susceptibility to NPPO. These include short neck, difficult intubation, endotracheal tube obstruction, history of obstructive sleep apnea, obesity, acromegaly, and upper airway surgery [6,12]. In addition, young healthy, and muscular patients, are frequently predisposed to this condition because of their ability to generate high amounts of negative intra-thoracic pressures during airway obstruction [13]. This was likely the case here as our patient was a young healthy and averagely built man. 
The pathogenesis of NPPO is multifaceted $[6,12,14]$. They include changes in Starling forces, hemodynamic changes due to increased negative intra-thoracic pressure, hypoxia, increased catecholamine levels and failure of lymphatic drainage. During strong inspiratory effort, negative intra-thoracic pressure can be as high as $-140 \mathrm{~cm} \mathrm{H}_{2} \mathrm{O}$ from normal value of $-4 \mathrm{~cm} \mathrm{H}_{2} 0$ [10].This leads to alteration in Starling forces and cause an increase in the hydrostatic pressure gradient favoring transudation of fluid from the pulmonary capillary to the pulmonary interstitial space. It also causes an increase in the venous return to the heart resulting in an increase in the pulmonary blood volume, pulmonary venous pressures causing an increase in the hydrostatic pressure gradient, and oedema formation. Since there was no history of cardiac disease in this patient, the acute onset of airway obstruction at the time of extubation, followed by desaturation, was more consistent with the clinical picture of NPPO hence the diagnosis.

Furthermore negative pulmonary pressure increases the mechanical stress on pulmonary capillaries. This resultsin mechanical disruption of the alveolar-capillary membrane with subsequent impairment of barrier function, aprocess termed "stress failure" [15]. Leading to increased capillary permeability and oedema formation $[14,16]$. The presence of frothy secretion with streaks of blood in the oropharynx of our patient is suggestive of pulmonary hemorrhage observed in our case indicates that this mechanism may be important in the development of NPPO.

Hypoxia occurring during laryngospasm and NPPO could trigger hypoxic pulmonary vasoconstriction (HPV) and raise pulmonary vascular resistance, thus increasing Trans mural hydrostatic pressures. This leads to right ventricular volume increase, with resultant reduction in left ventricular diastolic compliance. In addition, negative intra-thoracic pressure has a direct depressing effect on cardiac output by increasing the afterload [17]. Hypoxia-induced systemic and pulmonary vasoconstriction also increases afterload. This in combination with reduced myocardial contractility leads to a decrease in the left ventricular function, which in turn increases pulmonary venous pressure and further aggravates pulmonary edema.

Negative pressure pulmonary oedema, if recognized and treated early, is usually self-limiting and completely reversible [1,18]. Management is mainly supportive. The initial steps involve relieving the obstruction and maintaining patent airway and oxygenation. Although, it is said that not all patients will require reintubation, our patient was immediately reintubated to reverse the rapidly developing hypoxaemia. In the ICU, he was subsequently commenced on positive pressure ventilation, with the application of PEEP which have been used successfully $[1,19]$.

The use of diuretics in the management of NPPO remains controversial. This is because the primary problem is not fluid overload, but interstitial fluid shifts, induced by the negative intrathoracicpressure [11,15,20]. In the absence of fluid overload, diuretic treatment is usually not required and most patients recover quickly following relief of airway obstruction [21,22]. However, diuretic therapy is an essential component in treating hydrostatic pulmonary edema, and it is being used in some patients with acute lung injury. This informed the initial bolus dose of $80 \mathrm{mg}$ frusemide administered and was subsequently discontinued after initiation of positive pressure ventilation.

Interstitial pulmonary oedemacould lead to narrowing of the airway which improves dramatically with the administration of B2 agonist. In addition, it has been shown that beta agonists could increase the rate of alveolar fluid clearance via increased active cation transport, accelerating the remission of symptoms of pulmonary oedema [21]. While in the ICU, our patient was nebulized with albuterol, a B agonist and had incentive spirometry to improve lung expansion.

Furthermore, in NPPO, an increase in extravascular lung water decreases lung compliance and increases shunting with carbon dioxide retention. Our patient's initial arterial blood gas $(\mathrm{ABG})$ revealed respiratory acidosis $(\mathrm{pH}=6.5)$ At the point of collecting blood for ABG, he was breathing spontaneously, and had received an opioid (pentazocine) intra-operatively. This could have resulted in the retention of $\mathrm{CO}_{2}$. Other possible causes of pulmonary oedema were ruled out in this case as he had no history of cardiac or pulmonary pathology in the past. Aspiration pneumonitis was also unlikely. The chest $\mathrm{x}$ ray revealed bilateral infiltrates which was consistent with an acute event.

\section{Conclusion}

Negative Pressure Pulmonary Oedema can complicate an otherwise simple procedure like appendectomy under LMA. Prompt recognition and institution of diuretics and positive pressure ventilation with positive end expiration (PEEP) is sine quano to a good outcome.

\section{References}

1. McConkey PP (2000) Post-obstructive pulmonary oedema- a case series and review. Anaesth Intensive Care 28: 72-6.

2. Patton WC, Baker CL (2000) Prevalence of negative-pressure pulmonary oedema at an orthopaedic hospital. J South ZOrthop Assoc 9: 248-53.

3. Devys JM, Balleau C, Jayr C, Bourgain JL (2000) Bitting the laryngeal mask: an unusual cause of negative pressure pulmonary oedema. Can J Anaesth 47: 176-8. 4. Stix MS, Rodriguez-Sallaberry FE, Cameron EM, Teague PD, O'Connor CJ (2001) Esophageal aspiration of air through the drain tube of the Proseal laryngeal mask. AnesthAnalg 93: 1354-7.

5. Goldenberg JD, Portugal LG, Wenig BL, Weingarten RT (1997) Negative -pressure pulmonary oedema in the otolaryngology patient. Otolaryngol Head Neck Surg 117: 62-6.

6. Udeshi A, Cantie SM, Pierre E (2010) Postobstructive pulmonary oedema. J Crit Care 25: e501-5.

7. Ezri T, Priscu V, Szmuk P, Soroker D (1993) Laryngeal mask and pulmonary oedema. Anesthesiol 78: 219. 
8. Guffin TN, Har-el G, Sanders A, Lucente FE, Nash M (1995) Acute postobstructive oedema. Otolaryngol Head Neck Surg 112: 235-7.

9. Broccard AF, Liaudet L, Aubert JD, Schnyder P, Schaller MD (2001) Negative pressure post-trachaelextubation alveolar haemorrhage. AnesthAnalg 92: 273-5.

10. Fremont RD, Kallet RH, Matthay MA, Ware LB (2007) Postobstructive pulmonary oedema: a case for hydrostatic mechanisms. Chest 131: 1742-6.

11. Krodel DJ, Bittner EA, Abduknour R, Brown R, Eikerman M (2010) Case scenario: acute postoperative negative pressure pulmonary oedema. Anesthesiol 113: 200-7.

12. Lorch DG, Sahn SA (1986) Post-extubation pulmonary oedema following anaesthesia induced by upper airway obstruction. Are certain patients at increased risk? Chest 90: 802-5.

13. Holmes JR, Hensinger RN, Wojtys EW (1991) Postoperative pulmonary oedema in young, athletic adults. Am J Sports Med 19: 365-71.

14. Mussi RK, Toro IF (2008) Negative pressure pulmonary oedema and haemorrhage associated with upper airway obstruction. J Bras Pneumo 34: 420-4.

15. Schwartz DR, Maroo A, Malhotra A, Kesselman H (1999) Negative pressure pulmonary haemorrhage. Chest 115: 1194-7.

16. Patel AR, Bersten AD (2006) Pulmonary haemorrhage associated with negative pressure pulmonary oedema: a case report. Crit Care Resusc 18: 115-6.

17. Wise RA (1985) Effect of alterations of pleural pressure on cardiac output. South Med J 78: 423-8.

18. Deeptika K, Kenaan CA, Barrocas AM, Fonseca JJ, Bilkazi GB (1997) Negative pressure pulmonary oedema after acute upper airway obstruction. J ClinAnesth 9: 403-8.

19. Lang SA, Duncan PG, Shephard DA, Ha HC (1990) Pulmonary oedema associated with airway obstruction. Can J Anesth 37: 210-8.

20. Stawicki SP, Sarani B, Braslow BM (2008) Reexpansion pulmonary oedema. OPUS 12 Scientist 2: 29-31.

21. Koh MS, Hsu AA, Eng P (2003) Negative pressure pulmonary oedema in the medical intensive care unit. Intensive Care Med 29: 1601-4.

22. Aggarwal D, Stawicki SP, Sarani B, Braslow BM (2008) Point-counterpoint: the role of dieresis in the management of re-expansionpoulmonary oedema. OPUS 12 Scientist 2: 10. 